TAHKIM, Jurnal Peradaban dan Hukum Islam. Vol.3 No.l (Maret, 2020) | ISSN : 2597-7962

\title{
ANALISIS FIKIH WAKAF DAN UNDANG-UNDANG NOMOR 41 TAHUN 2004 TENTANG WAKAF TERHADAP PEROLEHAN HAK NADZIR PADA PENGELOLAAN WAKAF UANG NADZIR INDIVIDU DIKAMPUNG TAPOS CIKALONG WETAN
}

\author{
Ifa Hanifia Senjiati, Siska Lis Sulistiani, Muhammad Fikri Rais Mubarok \\ Fakultas Syariah Universitas Islam Bandung \\ ifa.wahyudin@gmail.com
}

\begin{abstract}
ABSTRAK
Perkembangan wakaf saat ini sudah diberdayakan dalam bentuk aset uang yang disebut wakaf uang. Aset berupa uang dapat dikelola untuk usaha produktif. Salah satu usahanya dalam bidang peternakan. Namun di Kampung Tapos Cikalong Wetan terjadi penguasaan atas hasil pengelolaan wakaf uang. Dimana keuntungannya dikuasai oleh nadzir sepenuhnya. Padahal berdasarkan UUD No 41 Tahun 2004 tentang Wakaf nadzir hanya berhak memperoleh $10 \%$. Metode Penelitian yang digunakan kualitatif dengan pendekatan yuridis normatif. Sumber data primer berupa wawancara pada wakif dan nazhir di Desa Cikalong Wetan dan data sekunder berupa jurnal, buku dan literatur lainnya. Analisis data berupa perbandingan fikih wakaf dan Undang-Undang Nomor 41 dengan di lapangan kemudian diverifikasi lalu penarikan kesimpulan. Hasil Penelitian ini Pertama, Analisis Fikih Wakaf dan Undang-Undang Nomor 41 tentang perolehan hak nadzir adalah diperbolehkan mengambil keuntungan yang besarnya tidak lebih dari 10\%. Kedua, pengelolaan wakaf uang yang terjadi di Kampung Tapos Cikalong Wetan nadzir menguasai seluruh hasil usaha wakaf produktif. Ketiga, Analisis Fikih Wakaf dan Undang-Undang Nomor 41 nadzir di Kampung Tapos Cikalong Wetan belum mentaati peraturan yang telah ditentukan terkait upah nadzir.
\end{abstract}

\section{Kata Kunci : Wakaf Uang, Nadzir, Undang-Undang}

\section{ABSTRACT}

The development of waqf is now empowered in the form of money asets called waqf money. Money asets can be managed for productive businesses - one of the firms in the field of animal husbandry. However, in Tapos Cikalong Wetan Village, there is control over the results of money waqf management. In which the profit is controlled by nadzir completely. Whereas, based on Constitution No. 41 of 2004 concerning Nadzir's Waqf, it is only entitled to get $10 \%$. The research method used in this study was qualitative with a normative juridical approach. Primary data sources were interviews with wakif and nazhir in Cikalong Wetan Village, and secondary data were journals, books, and other literature. Data analysis was fiqih waqf comparisons, and Constitution Number 41 with in the field then verified then concluding.The result of this study showed that, First, Analysis of Fiqih Waqaf and Constitution Number 41 concerning the obtaining nadzir rights were permitted 
to take profits in the amount of not more than 10\%. Second, the management of money waqf in Tapos Cikalong Wetan Village controlled all the results of productive waqf. Third, Analysis of Fiqih Waqaf and Constitution Number 41, nadzir in Tapos Cikalong Wetan Village had not obeyed the rules that have been determined regarding the wages of nadzir.

Keywords: Money Waqf, Nadzir, Constitution.

\section{A. PENDAHULUAN}

Perkembangan wakaf saat ini bukan hanya difahami sebagai aset tetap yang hanya diperuntukkan untuk sarana ibadah, Pendidikan dan kesehatan. Namun, wakaf berkembang pada pengelolaan aset bergerak yang salah satu contohnya adalah aset bergerak berupa uang. Wakaf uang adalah wakaf yang dilakukan oleh seseorang, kelompok orang, lembaga atau badan hukum dalam bentuk uang tunai, termasuk dalam pengertian ini adalah suratsurat berharga ${ }^{1}$.

Pengelolaan wakaf dapat dikelola oleh perseorangan, organisasi atau badan hukum $^{2}$. Yang harus memenuhi persyaratan warga negara Indonesia, beragama Islam, dewasa, amanah, mampu secara jasmani dan rohani dan tidak terhalang melakukan perbuatan hukum ${ }^{3}$. Pada pembahasan penelitian ini, nadzir yang dimaksud adalah nadzir individu. Hal ini disebabkan oleh terjadinya pengelolaan asset wakaf yang tidak sesuai dengan aturan. Praktik pengelolaan wakaf uang oleh nadzir individu ditemukan di Kampung Tapos Desa Kanangasari Kecamatan Cikalong Wetan Kabupaten Bandung Barat.

Praktik pengelolaan wakaf uang yang dilakukan adalah penyerahan asset wakaf berupa sejumlah uang dari wakif (orang yang berwakaf) yaitu kepala madrasah kepada salah satu pengajar di madrasah tersebut yang selanjutnya disebut nadzir (pengelola asset

\footnotetext{
${ }^{1}$ Majelis Ulama Indonesia, Keputusan Fatwa Komisi Fatwa Majelis Ulama Indonesia tentang Wakaf Uang. Jakarta,2002.

${ }^{2}$ Undang-Undang No 41 Tahun 2004 tentang wakaf Pasal 9.

${ }^{3}$ Ibid, Pasal 10.
} 
TAHKIM, Jurnal Peradaban dan Hukum Islam. Vol.3 No.l (Maret, 2020) | ISSN : 2597-7962

wakaf). Dana tersebut digunakan untuk modal usaha ${ }^{4}$ ternak kambing yang tujuannya adalah untuk meningkatkan ekonomi masyarakat yang ada di Kampung Tapos ${ }^{5}$. Hal ini sejalan dengan hasil penelitian yang menjelaskan bahwa wakaf uang memilik peran penting dalam upaya pengentasan kemiskinan ${ }^{6}$. Hasil yang diperoleh dari usaha itu seharusnya diberikan kepada pihak yang berhak menerima wakaf (Mauquf'alaih), dan nazhir sebagai pengelola dana wakaf itu diperbolehkan mengambil keuntungan yang jumlahnya tidak lebih dari $10 \%$ (sepuluh persen) ${ }^{7}$. Hal ini sejalan dengan penelitian yang menjelaskan bahwa hasil investasi dialokasikan untuk upah nazhir (maksimal 10\%) dan kesejahteraan masyarakat (minimal 90\%) ${ }^{8}$.

Berdasarkan hasil wawancara dengan nadzir bahwa keuntungan yang diperoleh dari hasil usaha ternak kambing tersebut diambil seluruhnya oleh nazhir. ${ }^{9}$ Seharusnya, pengelolaan wakaf mengikuti peraturan undang-undang Pasal 12 nomor 41 tahun 2004 tentang wakaf yang mengatur besaran upah yang diperbolehkan oleh pengelola wakaf (nazhir) yang besarnya tidak melebihi 10\% (sepuluh persen) agar hasil dari pengelolaan wakaf dapat diberikan manfaatnya kepada mauquf alaih. Oleh karena itu, terdapat masalah penelitian yaitu adanya ketidaksesuaian antara undang-undang dengan fakta. Hal ini disebabkan karena nadzir individu tidak memiliki kompetensi yang cukup dalam mengelola wakaf produktif $^{10}$ sehingga optimalisasi untuk kesejahteraan wakaf tidak tercapai $^{11}$.

${ }^{4}$ Novie Fauziah, Dana Wakaf Dijadikan Modal Usaha Umat, Bagaimana Hukumnya?. Dipublish tanggal 15 November 2019. https://muslim.okezone.com/read/2019/11/15/614/2130460/dana-wakafdijadikan-modal-usaha-umat-bagaimana-hukumnya

${ }^{5}$ Wawancara dengan Bapak Farhahd selaku Wakif, pada tanggal 28 Mei 2019, pukul 14.00 WIB.

${ }^{6} \mathrm{M}$. Nur Rianto Al Arif, Wakaf Uang dan Pengaruhnya terhadap Program Pengentasan Kemiskinan di Indonesia, Indo-Islamika, Volume 2, Nomor 1, 2012/1433, hlm 17-29

${ }^{7}$ Undang-Undang No 41 Tahun 2004 tentang wakaf Pasal 12

${ }^{8}$ M Nur Rianto Al Arif, Pemberdayaan Masyarakat Berbasis Wakaf Uang, Jurnal Asy-Syir'ah Fak.Syariah UIN Sunan Kalijaga Yogyakarta, Vol. 44, No. II tahun 2010, hlm.813 - 828.

${ }^{9}$ Wawancara bersama nazhir selaku pengelola wakaf uang di Kampung Tapos Cikalong wetan, tanggal 10 mei 2019, pukul 14.00 .

${ }^{10}$ Iwan Agustiawan Fuad, Kurang Produktif, Baru $62 \%$ Tanah Wakaf di Indonesia Punya Sertifikat, dipublish tanggal 9 November 2017, https://katadata.co.id/berita/2017/11/09/kurang-produktif-baru-62tanah-wakaf-di-indonesia-punya-sertifikat

${ }^{11}$ Muhammad Alfin Syauqi, Optimalisasi Pengelolaan Wakaf Uang Untuk Kesejahteraan Umum The Optimalization Of Wakaf Money For Public Prosperity. Kanun Jurnal Ilmu Hukum No. 63, Th. XVI (Agustus, 2014), pp. 369-383 
TAHKIM, Jurnal Peradaban dan Hukum Islam. Vol.3 No.l (Maret, 2020) | ISSN : 2597-7962

Tujuan penelitian ini untuk mengetahui analisis fikih wakaf dan undang-undang nomor 41 tahun 2004 tentang wakaf terhadap perolehan hak nadzir atas pengelolaan wakaf uang, untuk mengetahui pengelolaan wakaf uang pada nadzir individu di Kampung Tapos Cikalong Wetan dan untuk mengetahui analisis fikih wakaf dan undang-undang nomor 41 tahun 2004 tentang wakaf terhadap perolehan hak nadzir di Kampung Tapos Cikalong Wetan.

\section{B. METODE PENELITIAN}

Metode ini menggunakan metode penelitian kualitatif dengan jenis yuridis normatif. Yuridis Normatif yaitu tipe penelitian yang difokuskan untuk mengkaji penerapan kaidah-kaidah atau norma-norma dalam hukum positif. Penelitian normatif dapat diartikan sebagai penelitian yang dilakukan dengan cara meneliti bahan pustaka atau data sekunder yang terdiri dari bahan primer, bahan hukum sekunder, dan bahan hukum tersier. Bahan-bahan tersebut disusun secara sistematis, dikaji kemudian ditarik kesimpulan dalam hubungannya dengan masalah yang diteliti ${ }^{12}$. Jenis dan sumber data yang digunakan pada penelitian ini adalah menggunakan data primer berupa wawancara kepada wakif dan nadzir.

Sumber data yang digunakan adalah (1) data hukum primer berupa UndangUndang Nomor 41 Tahun 2004 tentang wakaf, Peraturan Pemerintah Nomor 42 Tahun 2006 Tentang Pelaksanaan Undang-Undang Nomor 41 Tahun 2004 tentang Wakaf, AlQur'an dan Hadist. (2) Data hukum sekunder berupa Jurnal, Skripsi, dan Buku dan (3) Data hukum tersier berupa wawancara.

Pengolahan data tahap awal dilakukan proses pengumpulan data. Setelah data-data terkumpul maka penulis menganalisis dengan menggunakan metode deskriptif kualitatif. Data dalam penelitian kualitatif bukan hanya sekedar terkait dengan kata-kata, tetapi sesungguhnya yang dimaksud dengan penelitian kualitatif afalah segala sesuatu yang diperoleh dari yang dilihat, didengar, diamati, dan kemudian diolah ${ }^{13}$.

\footnotetext{
12 Bambang Sugono, Metodologi Penelitian Hukum, (Jakarta : Rajagrafindo Persada, 2006), hlm. 107.

13 Muhammad Idrus, Metode Penelitian Ilmu Sosial: Pendekatan Kuantitatif dan Kualitatif, Edisi Kedua, (Jakarta: Erlangga, 2009), hlm.148.
} 
TAHKIM, Jurnal Peradaban dan Hukum Islam. Vol.3 No.l (Maret, 2020) | ISSN : 2597-7962

Pendekatan penelitian adalah Yuridis Normatif adalah adalah pendekatan yang dilakukan berdasarkan bahan hukum utama dengan cara menelaah teori-teori, konsepkonsep, asas-asa hukum serta peraturan perundang-undangan yang berhubungan dengan penelitian ini $^{14}$. Hubungan dengan penelitian yang akan penulis lakukan ialah penulis menjadikan undang-undang sebagai bahan utama.

\section{PEMBAHASAN}

\section{Fikih Wakaf}

Fikih wakaf menurut para fuqaha adalah menahan hartanya dan menyedekahkan manfaatnya untuk kebaikan agar dapat mendekatkan diri pada Allah SWT. Pendapat para Fuqaha tentang perolehan hak nadzir atas pengelolaan wakaf : Menurut ulama Hanafi, nazhir berhak menerima upah ketika ia melaksanakan tugas-tugasnya. Besaran upah yang diterima nazhir berkisar antara 1/10 (sepersepuluh), 1/8 (seperdelapan), dan sebagainya berdasarkan ketentuan wakif. Apabila wakif tidak menetapkan besaran upah yang diterima nazhir maka bisa ditetapkan oleh hakim ${ }^{15}$.

Menurut ulama Maliki, senada dengan pendapat diatas, tetapi ada sebagian dari ulama Malikkiyah yang berpendapat apabila wakif tidak menentukan upah nazhir maka hakim dapat membayar dari kas negara ${ }^{16}$. Menurut ulama Hambali, berpendapat bahwa nazhir berhak mendapat upah yang ditentukan wakif. Apabila wakif tidak menentukan upah atau gaji, dalam madzhab ini terdapat dua pendapat. Pertama, tidak halal bagi nazhir memperolehupah melainkan hanya diperbolehkan untuk makan seperlunya. Kedua, nazhir berhak memperoleh gaji atau upah sesuai pekerjaan yang menjadi tanggung jawabnya ${ }^{17}$.

Menurut Imam Syafi'I, berpendapat bahwa menetapkan gaji nadzir itu wakif, mengenai jumlah sesuai dengan ketentuan yang telah ditetapkan oleh wakif. Jika wakif

\footnotetext{
${ }^{14}$ Ibrahim Johnny, Teori dan Metodologi Penelitian Hukum Normatif, (Malang: Bayumedia Publishing, 2009), hlm. 295.

15 Yayah Rodiyah, Tinjauan Hukum Islam Terhadap Honor Nadzir Wakaf dan Amil Zakat, Program Studi Hukum Ekonomi Syariah Universitas Islam Negeri Syarif Hidayatullah Jakarta, hlm, 93.

${ }^{16}$ Ibid, hlm, 95.

${ }^{17}$ Ibid, hlm, 96.
} 
tidak menetapkan upah atau imbalan nadzir menurut Imam Syafi'I nadzir tidak berhak mendapatkan upahnya ${ }^{18}$.

\section{Landasan Hukum Wakaf}

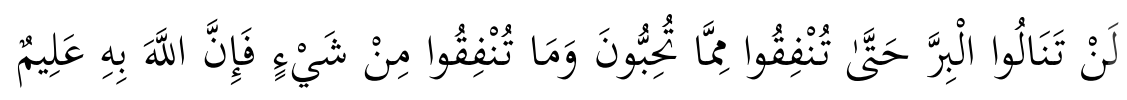

"Kamu sekali-kali tidak sampai kepada kebajikan (yang sempurna), sebelum kamu menafkahkan sehahagian harta yang kamu cintai. Dan apa saja yang kamu nafkahkan maka sesungguhnya Allah mengetahuinya." (Q.S. Al-Imran [3] : 92) ${ }^{19}$

Wakaf dalam Al-Quran tidak dijelaskan kalimat wakaf secara khusus, sehingga ayatnya bersifat umum salah satu diantaranya adalah menafkahkan harta, infak dana amal jariyah. Menafkahkan harta yang disebut dalam Al-Qur`an tidak kurang dari 72 tempat, selain berkonotasi pada nafkah wajib, seperti zakat atau memberi nafkah keluarga, juga menunjuk hukum sunnah, seperti sedekah, hibah, wakaf dan lain-lain. Selain itu Allah SWT menjanjikan kepada orang yang menafkahkan sebagian hartanya, dilipatgandakan pahalanya $700 \mathrm{kali}^{20}$.

\section{Pengertian Nadzir}

Nazhir adalah pihak yang menerima harta benda wakaf dari wakif untuk dikelola dan dikembangkan sesuai dengan peruntukannya. ${ }^{21}$. Kehadiran nadzir dirasa sangat penting agar tujuan wakaf dapat terpenuhi. Nadzir sendiri bisa bersifat perseorangan maupun kelembagaan (baik lembaga yang memiliki badan hukum maupun organisasi kemasyarakatan). Nadzir diharapkan mampu menjalankan tugasnya secara professional untuk menjaga dan mengembangkan harta benda wakaf, sehingga manfaat dari wakaf dapat terus diberikan pada pihak penerima wakaf. Namun tidak berarti nadzir memiliki kekuasaan mutlak terhadap harta benda wakaf. ${ }^{22}$

\footnotetext{
hlm.269.

${ }^{20}$ Wahbah Az-Zuhaili, Wahbah Az-Zuhaili, Fiqh Islam Wa Adillatuhu, (Jakarta: Gema Insani, 2011),

${ }^{21}$ Pasal 1 Undang-Undang 41 Tahun 2004 tentang Wakaf

${ }^{22}$ Sri Nurhayati dan Suryani, Akuntansi dan Manajemen Wakaf, (Jakarta : Salemba Empat, 2019),
} Ilmu, 2011).

${ }^{18}$ Ibid, hlm, 97.

${ }^{19}$ Q.S. Al-Imran [3] : 92. Kemenag RI, Al-qur`an dan Terjemahannya, (Bandung: Mikraj Khazanah hlm. 28 . 
TAHKIM, Jurnal Peradaban dan Hukum Islam. Vol.3 No.l (Maret, 2020) | ISSN : 2597-7962

\section{Hak Nadzir Menurut Fikih Wakaf dan Undang-Undang Nomor 41 Tahun 2004 tentang Wakaf}

Seorang nadzir berhak mendapatkan bagian dari hasil usaha wakaf produktif yang ia kelola dan kembangkan. Hal ini berdasarkan praktek sahabat Umar Bin Khatab dan Ali Bin Abu Thalib. Menurut madzhab Hanafi, Maliki dan Imam Ahmad nadzhir berhak mendapat upah dari hasil usaha harta wakaf yang telah dikembangkan. Adapun besarnya berbeda satu sama lain sesuai dengan tanggung jawab dan tugas yang diembankan. Tetap sesuai dengan ketentuan wakif, jika wakif tidak menetapkan, maka ditetapkan oleh hakim atau kesepakatan oara pengelola/managemen wakaf yang ada. Sementara madzhab Syafi'I menyatakan bahwa wakif tidak berhak mendapatkan bagian. ${ }^{23}$

Nazhir didalam melaksanakan tugasnya dapat menerima imbalan dari hasil bersih atas pengelolaan dan pengembangan harta benda wakaf yang besarnya tidak melebihi 10\% (sepuluh persen). Dalam melaksanakan tugasnya nazhir akan mendapatkan pembinaan dari Menteri dan Badan Wakaf Indonesia. ${ }^{24}$

\section{Hasil Penelitian}

\section{a. Analisis Fikih Wakaf dan Undang-Undang No. 41 Tahun 2004 tentang Wakaf terhadap Perolehan Hak Nadzir Atas Pengelolaan Wakaf}

Berdasarkan fikih wakaf atas pendapat para fuqaha maka perolehan hak nadzir atas pengelolaan wakaf menurut ulama Hanafi, Maliki, Hanafi, dan Hambali menjelaskan bahwa nazhir berhak menerima keuntungan dari hasil pengelolaan harta benda wakaf yang ia kelola. Besaran upah yang didapat nazhir dari hasil pengelolaannya itu jumlahnya sesuai dengan yang telah ditentukan oleh wakif. Apabila wakif tidak menentukan besaran upahnya maka yang berhak menentukan upahnya ialah hakim. Sedangkan menurut Imam Syafi'I nadzir tidak berhak mengambil upah daris hasil pengelolaan wakaf. Sementara itu, berdasarkan Pasal 12 Undang-Undang Nomor 41 Tahun 2004 tentang wakaf telah

23 Dadan Nasuha, Hak dan Kewajiban Nazhir, artikel di http://bwikotamalang.com/hak-dankewajiban-nadzir, diakses pada 1 juli 2019, pukul 08.20 WIB.

${ }^{24}$ Pasal 12 dan 13 Undang-Undang No. 41 Tahun 2004 tentang wakaf. 
TAHKIM, Jurnal Peradaban dan Hukum Islam. Vol.3 No.l (Maret, 2020) | ISSN : 2597-7962

ditentukan besaran upah yang berhak diterima oleh nazhir jumlahnya tidak melebihi $10 \%$ (sepuluh persen).

\section{b. Analisis Pengelolaan Wakaf Uang Pada Nadzir Individu di Kampung Tapos Kec. Cikalong Wetan}

Wakaf uang yang terjadi di Kampung Tapos Kec. Cikalong Wetan Kab. Bandung Barat terjadi pada April 2013 dalam bentuk uang sebesar Rp. 13.000.000 dengan tujuan untuk membantu perekonomian masyarakat di Kampung Tapos. Uang yang diwakafkan oleh wakif diberikan kepada nazhir secara lisan untuk dijadikan modal usaha. Manfaat dari wakaf uang tersebut harus dapat dirasakan oleh masyarakat yang ada di Kampung Tapos. Uang yang diberikan pewakif dikelola oleh nadzir untuk di belikan 8 ekor kambing yang harganya sebesar Rp.1.000.000/ekor dan sisa dari uang wakaf tersebut yaitu sebesar Rp.5.000.0000 untuk dijadikan biaya pembangunan kandang kambing. Peruntukkan harta benda yang telah diwakafkan sesuai dengan amanah dari wakif. Sampai saat ini kambing yang ada dipeternakan Kampung Tapos itu jumlahnya masih tetap sama yaitu sebanyak 8 ekor.

Seiring berjalannya waktu, pengelolaan wakaf uang yang terjadi di Kampung Tapos Cikalong Wetan dikelola secara produktif pada aset peternakan kambing dan telah menjadi salah satu peternakan kambing yang menyediakan kebutuhan-kebutuhan hewan kurban khususnya kambing. Kambing yang dijual di peternakan kampung Tapos itu harganya setiap tahun mengalami kenaikan yang perubahannya tidak terlalu signifikan. Hingga saat ini, peternakan dari hasil pengelolaan dan pengembangan wakaf uang di Kampung Tapos telah berkembang dan mempunyai keuntungan yang dihasilkam dari jual beli kambing tersebut. Keuntungan yang diperoleh dari jual beli kambing tersebut hasilnya diambil seluruhnya oleh nadzir (pengelola wakaf), seharusnya keuntungan yang diperoleh dari jual beli kambing tersebut disalurkan atau diberikan untuk kemaslahatan mauquf alaih. Mauquf alaih disini yaitu masyarakat Kampung Tapos, Mauquf alaih akan diberi penawaran harga yang lebih murah apabila ingin membeli kambing. 
TAHKIM, Jurnal Peradaban dan Hukum Islam. Vol.3 No.l (Maret, 2020) | ISSN : 2597-7962

Berdasarkan hal tersebut maka pengelolaan wakaf uang di Kampung Tapos Kec. Cikalong Wetan Kab. Bandung Barat belum mengikuti peraturan yang telah ditetapkan. Hal ini dikarenakan kurangnya pemahaman nazhir sebagai pengelola dalam memanfaatkan harta benda wakaf tersebut.

\section{SIMPULAN}

Hasil penelitian berdasarkan pembahasan di atas, maka dapat di tarik simpulan sebagai berikut :

a. Analisis Fikih Wakaf dan Undang Undang 41 Tahun 2004 tentang wakaf terhadap perolehan hak nadzir atas pengelolaan wakaf uang adalah bahwa nazhir berhak menerima keuntungan dari hasil pengelolaan harta benda wakaf yang ia kelola. Besaran upah yang didapat nazhir dari hasil pengelolaannya itu jumlahnya sesuai dengan yang telah ditentukan oleh wakif. Apabila wakif tidak menentukan besaran upahnya maka yang berhak menentukan upahnya ialah hakim. Namun, Imam Syafi'I berpendapat bahwa nadzir tidak memperoleh upah dari pengelolaan wakaf. Sementara itu, berdasarkan Pasal 12 Undang-Undang Nomor 41 Tahun 2004 tentang wakaf telah ditentukan besaran upah yang berhak diterima oleh nazhir jumlahnya tidak melebihi $10 \%$ (sepuluh persen).

b. Pengelolaan wakaf uang yang terjadi di Kampung Tapos Kec. Cikalong Wetan Kab. Bandung Barat adalah aset wakaf berupa uang yang diberikan dari wakif dikelola oleh nadzir untuk wakaf produktif berupa usaha peternakan kambing dengan hasil usaha dikuasai seluruhnya oleh nadzir dan untuk mauquf alaihnya yaitu masyarakat yang diberikan penawaran harga murah jika membutuhkan kambing.Analisis Fikih Wakaf dan Undang-Undang No. 41 Tahun 2004 terhadap perolehan hak nazhir di Kampung Tapos Kec. Cikalong Wetan Kab. Bandung Barat adalah secara fikih hak nadzir tidak ditentukan oleh wakif dan hakim. Sehingga perolehan hak nadzir di Kampung Tapos Cikalong wetan tidak sesuai dengan fikih wakaf. Begitu pula tidak sesuai dengan UU 41 Tahun 2004 Pasal 12 yang memberi hak nadzir sebesar $10 \%$. 
TAHKIM, Jurnal Peradaban dan Hukum Islam. Vol.3 No.l (Maret, 2020) | ISSN : 2597-7962

\section{DAFTAR PUSTAKA}

\section{Al-Quran :}

Al-qur`an dan Terjemahannya, Kemenag RI, Bandung: Mikraj Khazanah Ilmu, 2011.

\section{Undang-Undang :}

Majelis Ulama Indonesia, (2002), Keputusan Fatwa Komisi Fatwa Majelis Ulama Indonesia tentang Wakaf Uang. Jakarta

Undang-Undang No 41 Tahun 2004 tentang wakaf

\section{Buku:}

Az-Zuhaili, W. (2011) Fiqh Islam Wa Adillatuhu, Jakarta: Gema Insani, 2011, hlm.269.

Idrus, M. (2009) Metode Penelitian Ilmu Sosial: Pendekatan Kuantitatif dan Kualitatif, Edisi Kedua, Jakarta: Erlangga, hlm.148.

Johnny, I. (2009) Teori dan Metodologi Penelitian Hukum Normatif, Malang: Bayumedia Publishing, hlm. 295.

Nurhayati, S. dan Suryani. (2019) Akuntansi dan Manajemen Wakaf, Jakarta Selatan : Salemba Empat.

Rodiyah, Y. (2018). Tinjauan Hukum Islam Terhadap Honor Nadzir Wakaf dan Amil Zakat, Program Studi Hukum Ekonomi Syariah Universitas Islam Negeri Syarif Hidayatullah Jakarta.

Sugono, B. (2006) Metodologi Penelitian Hukum, Jakarta : Rajagrafindo Persada.

\section{Jurnal:}

Al Arif, M. N. R. (2010). Pemberdayaan Masyarakat Berbasis Wakaf Uang, Jurnal AsySyir'ah Fak.Syariah UIN Sunan Kalijaga Yogyakarta, Vol. 44, No. II tahun 2010 .

(2012). Wakaf Uang dan Pengaruhnya terhadap Program Pengentasan Kemiskinan di Indonesia, Indo-Islamika, Volume 2, Nomor 1, 2012/1433.

Syauqi, M. A. (2014). Optimalisasi Pengelolaan Wakaf Uang Untuk Kesejahteraan Umum The Optimalization Of Wakaf Money For Public Prosperity. Kanun Jurnal Ilmu Hukum No. 63, Th. XVI (Agustus, 2014), pp. 369-383. 
TAHKIII, Jurnal Peradaban dan Hukum Islam. Vol.3 No.1 (Maret, 2020) | ISSN : 2597-7962

\section{Website :}

Fauziah, Novie (2019). Dana Wakaf Dijadikan Modal Usaha Umat, Bagaimana Hukumnya? Dipublish tanggal 15 November 2019. https://muslim.okezone.com/read/2019/11/15/614/2130460/dana-wakaf-dijadikanmodal-usaha-umat-bagaimana-hukumnya

Fuad, Iwan Agustiawan (2017). Kurang Produktif, Baru 62\% Tanah Wakaf di Indonesia Punya Sertifikat, dipublish tanggal 9 November 2017, https://katadata.co.id/berita/2017/11/09/kurang-produktif-baru-62-tanah-wakaf-diindonesia-punya-sertifikat

Nasuha, Dadan (2019). Hak dan Kewajiban Nazhir, artikel di http://bwikotamalang.com/hak-dan-kewajiban-nadzir, diakses pada 1 juli 2019, pukul 08.20 WIB.

\section{Pengumpulan Data :}

Wawancara dengan Bapak Farhahd selaku Wakif, pada tanggal 28 Mei 2019, pukul 14.00 WIB.

Wawancara bersama nazhir selaku pengelola wakaf uang di Kampung Tapos Cikalong wetan, tanggal 10 mei 2019, pulkul 14.00 
TAHKIM, Jurnal Peradaban dan Hukum Islam. Vol.3 No.l (Maret, 2020) | ISSN : 2597-7962 